area. All of the current cohort of 16 people are actively engaged with the service. The most common type of service delivered was for follow up with over 350 contacts provided over 12 months. On average there were four contacts per case per month ranging from one to 30 . Ninety-four percent are on medication $62.5 \%$ with undetectable HIV viral loads, and $62.5 \%$ with satisfactory CD4 counts. Since 1994 twelve of the cohort has died and there have been ten new notifications. There have been 30 pregnancies with two positive babies.

Conclusion Although challenges in obtaining ideal outcomes persist, a holistic service delivery characterised by the development and continuation of relationships with the service provided has resulted in complete engagement of this cohort and has achieved positive outcomes in $62.5 \%$ of cases. This model of care, although labour intensive, delivers results similar or better than those seen internationally in hard to reach populations It demonstrates that equal outcomes can be achieved when equitable services are provided in a culturally appropriate manner.

Disclosure of interest statement None No pharmaceutical grants were received in the development of this study.

\section{P01.06 ROLES OF NGOS/CSOS IN HIVIAIDS PREVENTION, TREATMENT, CARE AND SUPPORT FOR MOBILE POPULATION IN GREATER MEKONG SUB-REGIONS}

S Wagle*, S Talawat, P Panitchpakdi. Raks Thai Foundation, Bangkok, Thailand

\subsection{6/sextrans-2015-052270.216}

Introduction Thailand is a major destination for labour markets in Greater Mekong regions. Health services and medical treatment particularly HIV/AIDS treatment are important areas where migrant workers and their dependents have fallen through the cracks for both official and unofficial migrants working in Thailand. For official migrants there are Migrants health insurance package which cover the health services, Anti-Retroviral Treatment however for unofficial migrants is a huge obstacles and fear in accessing health care services. Civil Society Organisations in Thailand have attempted to fill some of these gaps particularly for unofficial migrants in HIV/AIDS prevention related to HIV and AIDS in mobile populations.

Methods Around $50 \mathrm{CSOs/NGOs} \mathrm{in} \mathrm{Greater} \mathrm{Mekong} \mathrm{Sub-}$ regions including countries like Myanmar, Cambodia, Laos, Vietnam, Thailand and China were contacted to participate in the project "Strengthening CSOs/NGOs in HIV/AIDS for Mobile Population in Greater Mekong Sub-regions" to help labour migrants access HIV/AIDS prevention, treatment, care and support. These NGOs were involved in capacity building of PLHIV peer networks, cross border meetings, cross learning visits to learn and share good practices in the region.

Results Almost $40 \mathrm{CSOs} / \mathrm{NGOSs}$ were participated in the project with an aim to help unofficial migrants access HIV/AIDS prevention, treatment, care and support. There are informal referral assisted by NGOs/CSOs. However, migrants with very low income are unable to afford to pay for and hence do not take medicine regularly. NGOs/CSOs shared their experiences and recommendations on making freely available Anti-Retroviral Therapy available in the source, transit and destination.

Conclusion HIV/AIDS prevention, treatment, care and support services should be available to migrants despite of their nationality and mobility. This requires policy level changes to scale up migrant's friendly referrals and communication approach in terms of ARVs treatment.

Disclosure of interest statement The project was supported by Asian Development Bank.

\section{P01.07 YOUNG QUEENSLAND SUDANESE'S SEXUAL HEALTH KNOWLEDGE AND BEHAVIOURS MAY PLACE THEM AT RISK - CULTURALLY INFORMED SEXUALITY EDUCATION IS NEEDED}

1f Dean*, ${ }^{1,2} \mathrm{M}$ Mitchell, ${ }^{3} \mathrm{~J}$ Debattistia, ${ }^{4} \mathrm{D}$ Stewart, ${ }^{5} \mathrm{~J}$ Wollin. ${ }^{1}$ School of Nursing and Midwifery, Centre for Health Practice Innovation, Menzies Health Institute Queensland, Griffith University; ${ }^{2}$ Nurse Practice Development Unit Princess Alexandra Hospital; ${ }^{3}$ Metro North Public Health Unit, Metro North Hospital and Health Service, Queensland Government; ${ }^{4}$ School of Medicine, Griffith University; ${ }^{5}$ Quality and Research Unit, Wesley Mission Brisbane

\subsection{6/sextrans-2015-052270.217}

Introduction Young people who have experienced forced migration are vulnerable in relation to their sexual health, however, little is known about their sexual health literacy and behaviours post resettlement. This study explored the sexual health knowledge, attitudes, and beliefs of young Sudanese Queenslanders along with the patterns of sexual behaviour and sexuality education of this predominately refugee background group.

Methods Conducted in partnership with the target community using a convergent parallel mixed methods design, this study involved a convenience sample of 16-24 year old Sudanese Queenslanders completing an anonymous self-administered written survey. Descriptive, correlational, and Multivariate Analysis of Variance statistics were conducted.

Results Of the 229 participants (Mean age $=19.2$ years), 95 males $(63.8 \%)$ and 45 females $(57.0 \%)$ self-reported they had experienced sex. The mean HIV knowledge score $(\mathrm{M}=6.8,12$ item, Cronbach's $\alpha=0.83$ ) was higher than the mean STI knowledge score $(\mathrm{M}=3.6,11$ item, Cronbach's $\alpha=0.67)$, importantly however, both were low. The majority had sought sexual health information $(61.1 \%)$ and self-reported they were confident talking about sex with partners $(72.1 \%)$. They were notably less confident talking about sex with parents (27.9\%). A third (31\%) reported a HIV test. The aggregated Sexual Risk Behaviour Score (25 items, Cronbach's $\alpha=0.9$, range 7 to 70 , $\mathrm{M}=27.91, \mathrm{SD}=14.1$ ) suggested generally low levels of risk behaviour. However, there was inconsistent condom use, minimal hormonal contraception use $(9.3 \%)$, and $3.1 \%$ reported sex leading to an STI, 9.0\% reported a pregnancy, 33.1\% had experienced unwanted sex, and $32.9 \%$ had practiced anal sex.

Conclusion There was clear evidence of behaviours that place this group at increased risk of negative sexual health outcome suggesting a strong need for culturally informed sexual health education and interventions that address these aspects early within the resettlement experience.

Disclosure of interest statement This research is part of the first authors Doctor of Philosophy through Griffith University. The study was supported by the Queensland Nursing Council Novice Researcher Grant (RAN 1034) and Centaur Memorial Fund for Nurses Scholarship. No pharmaceutical grants were received in the development of this study. 